The University of Southern Mississippi

The Aquila Digital Community

Faculty Publications

3-19-2004

\title{
Binary Frontal Polymerization: Velocity Dependence on Initial Composition
}

John A. Pojman

University of Southern Mississippi, john@pojman.com

Jerry A. Griffith

University of Southern Mississippi, griffith@usm.edu

H. Archie Nichols

University of Southern Mississippi

Follow this and additional works at: https://aquila.usm.edu/fac_pubs

Part of the Chemistry Commons

\section{Recommended Citation}

Pojman, J. A., Griffith, J. A., Nichols, H. A. (2004). Binary Frontal Polymerization: Velocity Dependence on Initial Composition. E-Polymers.

Available at: https://aquila.usm.edu/fac_pubs/9115

This Article is brought to you for free and open access by The Aquila Digital Community. It has been accepted for inclusion in Faculty Publications by an authorized administrator of The Aquila Digital Community. For more information, please contact Joshua.Cromwell@usm.edu. 


\title{
Binary frontal polymerization: Velocity dependence on initial composition
}

\author{
John A. Pojman *, Jerry Griffith, H. Archie Nichols \\ Department of Chemistry and Biochemistry, The University of Southern Mississippi, \\ Hattiesburg, MS, 39406-5043, USA; Fax (425) 740-8514; john@pojman.com
}

(Received: February 16, 2004; published: March 19, 2004)

\begin{abstract}
Frontal polymerization is a mode of polymerization in which a localized zone of reaction propagates through the coupling of thermal diffusion and the Arrhenius dependence of the reaction rate. The dependence of the front propagation velocity on the initial composition has been determined in initially miscible binary systems of a free-radically cured diacrylate and an amine- or cationically cured epoxy resin. A minimum of the velocity as a function of the monomer mole fraction is observed if the two polymerizations occur independently. Excellent agreement with an analytical description was found with the diacrylate and an amine-cured epoxy but not for a diacrylate and a cationically cured one because of the effect of $\mathrm{HCl}$ impurities on the peroxide.
\end{abstract}

\section{Introduction}

Frontal polymerization is a mode of converting monomer into polymer via a localized reaction zone that propagates through the coupling of thermal diffusion and the Arrhenius dependence of the reaction rate. Such fronts can exist with free-radical polymerization or epoxy curing. Frontal polymerization was first discovered at the Institute of Chemical Physics in Chernogolovka, Russia, by Chechilo and Enikolopyan in 1972 [1]. They studied methyl methacrylate polymerization to determine the effect of initiator type and concentration on front velocity [2] and the effect of pressure $[3,4]$. A great deal of work on the theory of frontal polymerization has been performed [5-10]. Davtyan et al. reviewed the field up to 1984 [11]. Pojman et al. reviewed and analyzed the chemistry and theory of frontal polymerization, and possible applications $[12,13]$. Washington and Steinbock reviewed free-radical frontal polymerization for applications to materials synthesis [14].

An overwhelming majority of work has been on free-radical systems, but other chemistries can be used. Begishev et al. studied frontal anionic polymerization of $\varepsilon-$ caprolactam [15,16] and epoxy chemistry has been used as well [17-20]. Mariani et al. demonstrated frontal ring-opening metathesis polymerization [21], and Fiori et al. produced polyacrylate/poly(dicyclopentadiene) networks frontally [22]. Polyurethanes have recently been prepared frontally $[23,24]$. Frontal atom transfer radical polymerization has recently been achieved [25]. Thiol-ene chemistry has also been used in frontal polymerization [26].

The factors affecting the velocity of frontal homopolymerization have been studied in great detail with acrylates [27]. In such systems the velocity increases monotonically 
with increasing initiator concentration. Tredici et al. studied the velocity dependence on initiator concentration for frontal copolymerization [28].

Perry et al. studied the velocity dependence for frontal copolymerization on the monomer feed composition and the reactivity ratios [29]. They observed that the velocity was a monotonic function of the initial comonomer composition. In other words, the velocity smoothly changed from the value for the frontal homopolymerization of one monomer to the velocity for the frontal homopolymerization for the other monomer, without passing through a minimum.

Pojman et al. studied binary frontal polymerization in which an interpenetrating polymer network (IPN) was produced by a propagating front through a solution of an epoxy resin (diglycidyl ether of bisphenol A, DGEBA) that was simultaneously cationically and amine-cured and a free-radically cured diacrylate (triethylene glycol dimethacrylate, TGDMA) [30]. Each resin component was assumed to react independently of the other. They found an interesting relationship for the front velocity as a function of the initial composition of the two components (Fig. 1). Contrary to what was observed for frontal copolymerization, the binary frontal polymerization exhibited a minimum at an intermediate composition. We set out to test if this was a general phenomenon of such binary systems in which two different polymerizations occur simultaneously but without copolymerization.

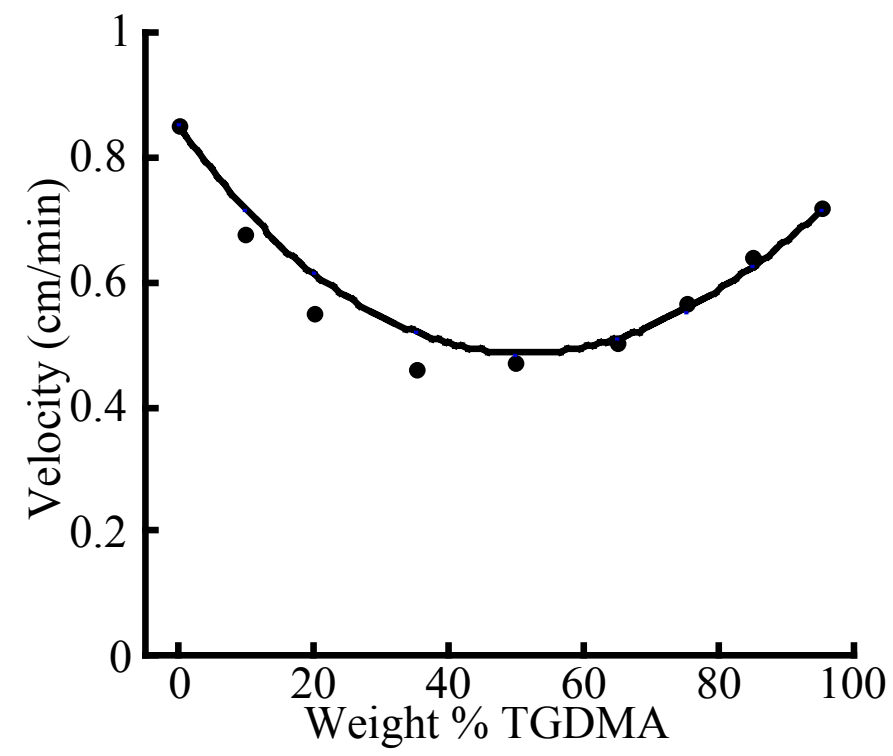

Fig. 1. The velocity as a function of the fraction of the triethylene glycol dimethacrylate (TGDMA) in the binary frontal polymerization with DGEBA that was cured with a mixture of amine and cationic curing agents. Adapted from Pojman et al. [30]. The solid line is the calculated velocity from Eq. (3) (see text for discussion)

\section{Results and discussion}

We required two simultaneous homopolymerizations without copolymerization. We used the free-radical polymerization of ethylene glycol dimethacrylate (EGDMA) with a peroxide initiator (Luperox 231). The other mechanisms we tested were the aliphatic-amine curing (using EPICURE 3271) of the epoxy resin diglycidyl ether of bisphenol $\mathrm{F}$ (DGEBF) and the cationically cured DGEBF with a $\mathrm{BCl}_{3}$ amine complex. Amine curing of an epoxy is a step-growth process. The $\mathrm{BCl}_{3}$-amine complex acts as an initiator for a cationic chain-growth polymerization of the epoxy. 
We studied the velocity dependence on the mole fraction of EGDMA for each system, viz., EGDMA with cationically cured DGEBF and EGDMA with amine-cured DGEBF. For the cationically cured epoxy with EGDMA the velocity dependence curve is not a simple concave-up function (Fig. 2). The assumption has been that each component reacts independently of the others, i.e., the $\mathrm{BCl}_{3}$-amine does not influence the freeradical polymerization of EGDMA. This is incorrect. We tested the effect of the $\mathrm{BCl}_{3}$ amine on the free-radical frontal polymerization of EGDMA. Fig. 3 shows that the addition of $25 \% \mathrm{BCl}_{3}$-amine increases the front velocity by $33 \%$.

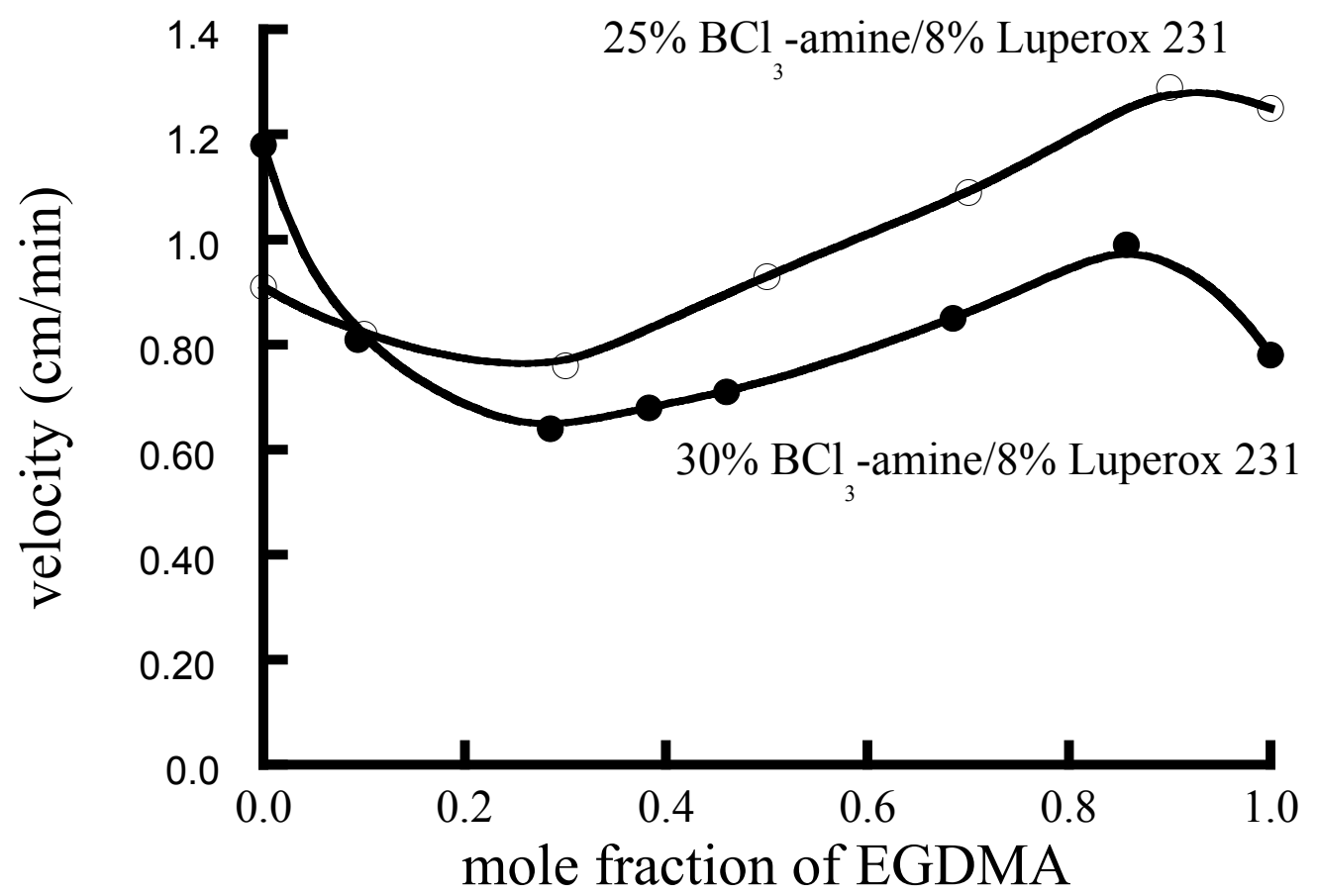

Fig. 2. Velocity as a function of EGDMA mole fraction in the binary frontal polymerization of EGDMA and DGEBF with $\mathrm{BCl}_{3}$-amine and Luperox 231

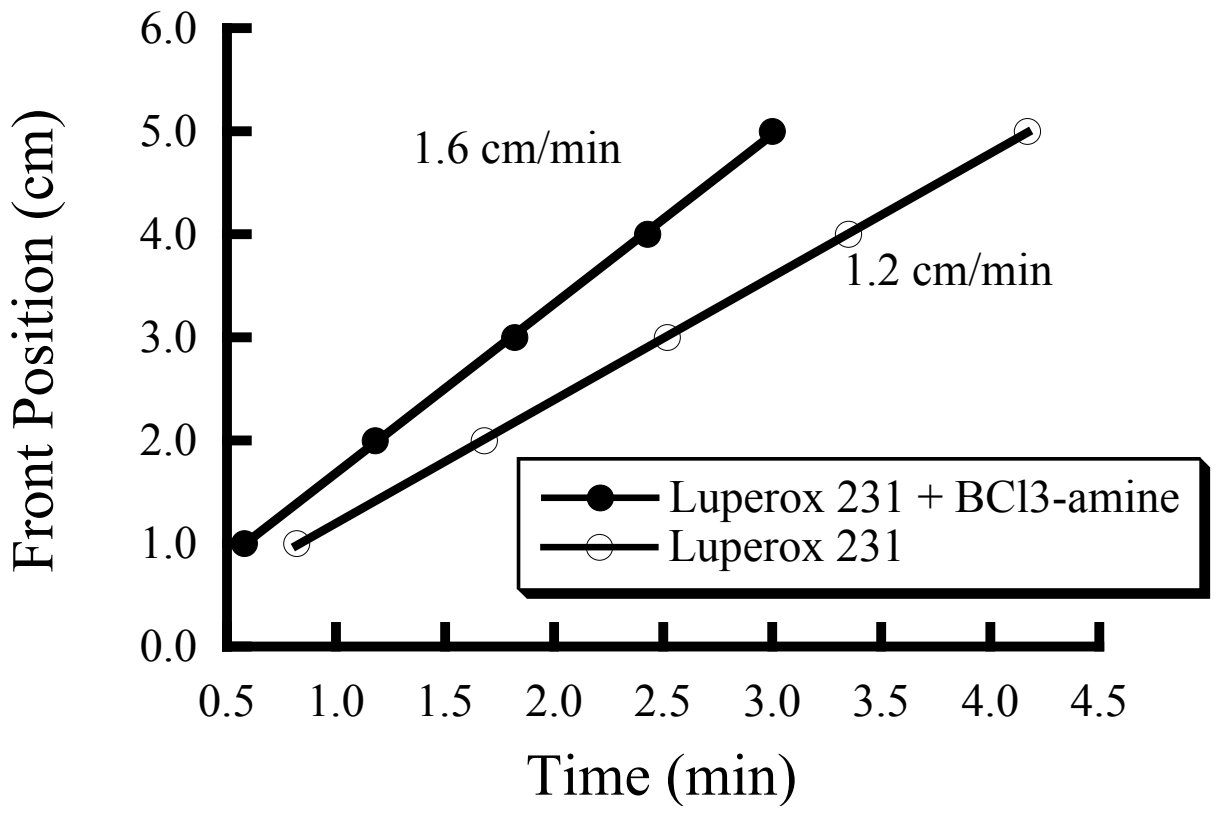

Fig. 3. The effect of $25 \%(\mathrm{w} / \mathrm{w}) \mathrm{BCl}_{3}$-amine on the free-radical frontal polymerization of EGDMA with Luperox231 as the initiator 
To determine the cause of this large increase in velocity, we measured the effect of $\mathrm{BCl}_{3}$-amine on the pot life at room temperature of Luperox 231 and EGDMA. EGDMA with $2 \%$ Luperox 231 did not react within one hour (its pot life is on the order of several days). However, EGDMA with $25 \% \mathrm{BCl}_{3}$-amine and $2 \%$ Luperox reacted within $5 \mathrm{~min}$. We suspected the component responsible for the rapid reaction was not the complex itself but rather $\mathrm{HCl}$, which would necessarily be present given that the $\mathrm{BCl}_{3}$-amine was not dry. EGDMA with 2\% Luperox 231 and $10 \%(\mathrm{v} / \mathrm{v})$ concentrated $\mathrm{HCl}$ reacted within 3 min. However, EGDMA with $10 \%$ concentrated $\mathrm{HCl}$ was not affected. Thus the $\mathrm{HCl}$ present in the $\mathrm{BCl}_{3}$-amine affects the rate of decomposition of the Luperox 231. The binary system of $\mathrm{BCl}_{3}$-amine-cured epoxy with peroxide-cured diacrylate does not consist of two independent mechanisms and thus its velocity dependence is not a simple concave-up function but exhibits a local maximum at 0.9 mole fraction of EGDMA.

However, the binary system with the amine-cured epoxy exhibits a single minimum (Fig. 4). We can understand this qualitatively by considering that as the concentration of one component is increased, the concentration of the other component is necessarily being decreased because both are miscible in each other. We can analyze it by considering the effect of the mole fraction of each component on the initial rate of an isothermal batch reaction. If we assume that the front velocity is a positive function of this initial rate, then our results should apply to the frontal case:

rate $=a(1-f)^{n}+b f^{m}$

where $f$ is the mole fraction of one component, $a$ and $b$ are constants related to the rate constants (and initiator concentration where applicable), and $n$ and $m$ are the orders of each reaction. We also must assume that this is the rate before significant phase separation occurs because otherwise the concentrations of each component would not be simply related to the initial mole fractions.

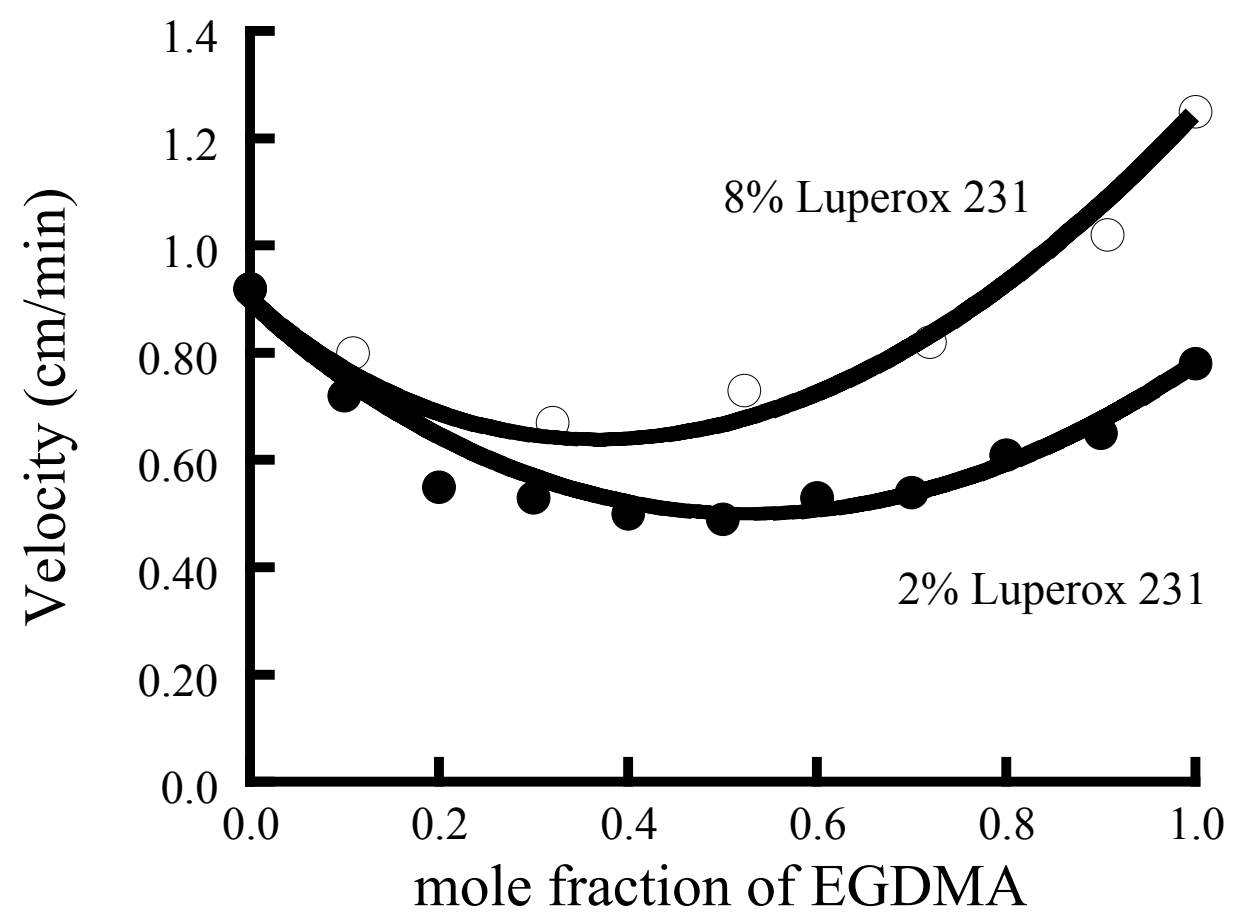

Fig. 4. Velocity as a function of EGDMA mole fraction in the binary frontal polymerization of EGDMA and DGEBF with Epicure 3271 and Luperox 231. Curves are calculated from Eq. (3) with no adjustable parameters 
We can determine the curvature of the rate dependence on $f$ by taking the second derivative of the rate with respect to $f$ :

$\partial^{2}$ rate $/ \partial f^{2}=n(n-1) a f^{n-2}+m(m-1) b(1-f)^{m-2}$

For $n, m>1$, this quantity will always be positive, and therefore, the rate dependence on $f$ will be a concave up function, as we observed experimentally.

We go a step further. We assume that we can replace the constants $a$ and $b$ in Eq. (1) with the homopolymerization front velocities, and replace $n$ by 2 (amine curing of epoxy is second order) and $m$ by $3 / 2$ for the free-radical polymerization reaction order, where $f$ is the fraction of EGDMA.

velocity $(f)=\operatorname{vel}(100 \%$ DGEBF $)(1-f)^{2}+\operatorname{vel}(100 \%$ EGDMA $) f^{3 / 2}$

We see in Fig. 4 that this function fits the data without any adjustable parameters.

If we look again at Fig. 1 we see that the curve calculated using Eq. (3) does not fit well. There are two reasons - the order of the reaction in the calculation was two for the epoxy reaction but the presence of the $\mathrm{BCl}_{3}$-amine means this is not correct. The order of the reaction is more complicated because two mechanisms of epoxy curing are occurring. It is interesting that there is not a local maximum at high EGDMA fractions, as seen in Fig. 2. The presence of the amine curing agents in the experiments for Fig. 1 could have neutralized the $\mathrm{HCl}$.

\section{Experimental part}

Frontal polymerizations were performed in $1.5 \mathrm{~cm}$ diameter test tubes with screw-on caps, which provided sufficient backpressure to prevent bubble formation. The initial solutions were poured into the tube and the cap sealed tightly. The tubes were inverted such that the caps were on the bottom, and the fronts were initiated with a soldering iron on the top. All reactions were performed behind a safety shield.

All frontal polymerizations were performed in descending mode to prevent buoyancydriven convection. Front velocities were determined from plots of the fronts' positions versus time.

Binary frontal polymerization was performed with solutions formed from two types of polymerization. The first was diethylene glycol dimethacrylate (EGDMA, 90\%) from Aldrich with Luperox 231 (1,1-di(tert-butylperoxy)-3,3,5-trimethylcyclohexane; Atofina) as the free-radical initiator. The second was bisphenol-F/epichlorohydrin epoxy resin (DGEBF, EPON 862, Shell, CAS \# 28064-14-4) cured in its stoichiometric ratio with the aliphatic amine curing agent (Epicure 3271, Shell, $34 \mathrm{~g}$ required to react with one equivalent of epoxide) or a $\mathrm{BCl}_{3}$-amine complex (Accelerator DY 9577, Ciba). The epoxy equivalent weight of DGEBF was 166 - 177 (grams of resin containing one gram equivalent of epoxide). The purity of the $\mathrm{BCl}_{3}$-amine complex was not provided by the manufacturer.

The concentration of a curing agent was calculated as a percentage of the respective component it was curing; for example, $2 \%$ Luperox 231 indicates $2 \%$ with respect to EGDMA no matter what the relative composition of EGDMA to DGEBF.

\section{Conclusions}

Binary frontal polymerization of two miscible monomers that polymerize by different mechanisms shows a minimum in the velocity dependence on the initial monomer 
solution composition if the mechanisms are truly independent of each other. For the binary system of a free-radical polymerized diacrylate and an aliphatic amine-cured epoxy, this is indeed true. This dependence can be predicted very well using a simple relationship involving the homopolymerization velocities, the reaction orders of each mechanism and the initial composition.

However, for the $\mathrm{BCl}_{3}$-amine-cured epoxy with the same diacrylate, the dependence was more complicated. We proposed that this is due to the catalytic effect of the $\mathrm{BCl}_{3}$-amine on the decomposition of the peroxide initiator.

Acknowledgement: Support for this project was provided by the National Science Foundation (CTS -0138660). We thank Terry Myers of Atofina for the donation of the Luperox 231.

[1] Chechilo, N. M.; Khvilivitskii, R. J.; Enikolopyan, N. S.; Dokl. Akad. Nauk SSSR 1972, 204, 1180.

[2] Chechilo, N. M.; Enikolopyan, N. S.; Dokl. Phys. Chem. 1975, 221, 392.

[3] Chechilo, N. M.; Enikolopyan, N. S.; Dokl. Phys. Chem. 1976, 230, 840.

[4] Chechilo, N. M.; Enikolopyan, N. S.; Dokl. Phys. Chem. 1974, 214, 174.

[5] Davtyan, S. P.; Surkov, N. F.; Rozenberg, B. A.; Enikolopyan, N. S.; Dokl. Phys. Chem. 1977, 232, 64.

[6] Davtyan, S. P.; Gel'man, E. A.; Karyan, A. A.; Tonoyan, A. O.; Enikolopyan, N. S.; Doklady Phys. Chem. 1980, 253, 579.

[7] Enikolopyan, N. S.; Kozhushner, M. A.; Khanukaev, B. B.; Dokl. Phys. Chem. 1974, 217, 676.

[8] Khanukaev, B. B.; Kozhushner, M. A.; Enikolopyan, N. S.; Dokl. Phys. Chem. 1974, 214, 84.

[9] Khanukaev, B. B.; Kozhushner, M. A.; Enikolopyan, N. S.; Combust. Explos. Shock Waves 1974, 10, 562.

[10] Surkov, N. F.; Davtyan, S. P.; Rozenberg, B. A.; Enikolopyan, N. S.; Dokl. Phys. Chem. 1976, 228, 435.

[11] Davtyan, S. P.; Zhirkov, P. V.; Vol'fson, S. A.; Russ. Chem. Rev. 1984, 53, 150.

[12] Pojman, J. A.; Ilyashenko, V. M.; Khan, A. M.; J. Chem. Soc., Faraday Trans. 1996, 92, 2825.

[13] Khan, A. M.; Pojman, J. A.; Trends Polym. Sci. 1996, 4, 253.

[14] Washington, R. P.; Steinbock, O.; Polymer News 2003, 28, 303.

[15] Begishev, V. P.; Volpert, V. A.; Davtyan, S. P.; Malkin, A. Y.; Dokl. Akad. Nauk SSSR 1973, 208, 892.

[16] Begishev, V. P.; Volpert, V. A.; Davtyan, S. P.; Malkin, A. Y.; Dokl. Phys. Chem. 1985, 279, 1075.

[17] Davtyan, S. P.; Arutyunyan, K. A.; Shkadinskii, K. G.; Rozenberg, B. A.; Yenikolopyan, N. S.; Polym. Sci. USSR 1978, 19, 3149. 
[18] Korotkov, V. N.; Chekanov, Y. A.; Rozenberg, B. A.; Comp. Sci. Tech. 1993, 47, 383.

[19] White, S. R.; Kim, C.; J. Reinforced Plastics Comp. 1993, 12, 520.

[20] Chekanov, Y.; Arrington, D.; Brust, G.; Pojman, J. A.; J. Appl. Polym. Sci. 1997, 66, 1209.

[21] Mariani, A.; Fiori, S.; Chekanov, Y.; Pojman, J. A.; Macromolecules 2001, 34, 6539.

[22] Fiori, S.; Mariani, A.; Ricco, L.; Russo, S.; e-Polymers 2002, no. 29.

[23] Fiori, S.; Mariani, A.; Ricco, L.; Russo, S.; Macromolecules 2003, 36, 2674.

[24] Mariani, A.; Bidali, S.; Fiori, S.; Malucelli, G.; Sanna, E.; e-Polymers 2003, no. 44.

[25] Bidali, S.; Fiori, S.; Malucelli, G.; Mariani, A.; e-Polymers 2003, no. 60.

[26] Pojman, J. A.; Varisli, B.; Perryman, A.; Edwards, C.; Hoyle, C.; Macromolecules 2004, 37, 691.

[27] Goldfeder, P. M.; Volpert, V. A.; Ilyashenko, V. M.; Khan, A. M.; Pojman, J. A.; Solovyov, S. E.; J. Phys. Chem. B 1997, 101, 3474.

[28] Tredici, A.; Pecchini, R.; Morbidelli, M.; J. Polym. Sci., Part A: Polym Chem. 1998, 36, 1117.

[29] Perry, M. F.; Volpert, V. A.; Lewis, L. L.; Nichols, H. A.; Pojman, J. A.; Macromol. Theory Simul. 2003, 12, 276.

[30] Pojman, J. A.; Elcan, W.; Khan, A. M.; Mathias, L.; J. Polym. Sci., Part A: Polym. Chem. 1997, 35, 227. 